\title{
Chloroplast- or Mitochondria- Targeted DEAD-Box RNA Helicases Play Essential Roles in Organellar RNA Metabolism and Abiotic Stress Responses
}

\author{
Ghazala Nawaz and Hunseung Kang * \\ Department of Plant Biotechnology, College of Agriculture and Life Sciences, Chonnam National University, Gwangju, \\ South Korea
}

The yields and productivity of crops are greatly diminished by various abiotic stresses, including drought, cold, heat, and high salinity. Chloroplasts and mitochondria are cellular organelles that can sense diverse environmental stimuli and alter gene expression to cope with adverse environmental stresses. Organellar gene expression is mainly regulated at posttranscriptional levels, including RNA processing, intron splicing, RNA editing, RNA turnover, and translational control, during which a variety of nucleus-encoded RNA-binding proteins (RBPs) are targeted to chloroplasts or

OPEN ACCESS

Edited by:

Andy Pereira,

University of Arkansas, United States

Reviewed by:

Li-Fen Huang

Yuan Ze University, Taiwan

Christine Helen Foyer,

University of Leeds, United Kingdom

${ }^{*}$ Correspondence:

Hunseung Kang

hskang@jnu.ac.k

Specialty section:

This article was submitted to

Plant Abiotic Stress,

a section of the journal

Frontiers in Plant Science

Received: 09 February 2017

Accepted: 10 May 2017

Published: 24 May 2017

Citation:

Nawaz G and Kang H (2017) Chloroplast- or Mitochondria-Targeted DEAD-Box RNA Helicases Play

Essential Roles in Organellar RNA Metabolism and Abiotic Stress Responses. Front. Plant Sci. 8:871. doi: 10.3389/fpls.2017.00871 mitochondria where they play essential roles in organellar RNA metabolism. DEADbox RNA helicases (RHs) are enzymes that can alter RNA structures and affect RNA metabolism in all living organisms. Although a number of DEAD-box RHs have been found to play important roles in RNA metabolism in the nucleus and cytoplasm, our understanding on the roles of DEAD-box RHs in the regulation of RNA metabolism in chloroplasts and mitochondria is only at the beginning. Considering that organellar RNA metabolism and gene expression are tightly regulated by anterograde signaling from the nucleus, it is imperative to determine the functions of nucleus-encoded organellar RBPs. In this review, we summarize the emerging roles of nucleus-encoded chloroplastor mitochondria-targeted DEAD-box RHs in organellar RNA metabolism and plant response to diverse abiotic stresses.

Keywords: chloroplast, DEAD-box RNA helicase, mitochondria, RNA metabolism, stress response

\section{INTRODUCTION}

The biggest threat to the increasing population worldwide is the scarcity of food due to reducing crop yields caused by various abiotic and biotic stresses such as drought, cold, heat, high salinity, UV, bacteria, fungi, and viruses (Zsigmond et al., 2008; Nouri et al., 2015). As sessile organisms, plants have evolved various strategies to withstand these adverse environmental conditions (Komatsu and Hossain, 2013; Ranty et al., 2016). The survival of plants against these environmental stresses depends on their ability to recognize stress stimuli and adapt to such stresses by regulating the expression of stress-responsive genes in cellular organelles, nucleus, and cytoplasm. Photosynthesis in chloroplasts (Biswal et al., 2011; Ashraf and Harris, 2013; Komatsu and Hossain, 2013) and energy metabolism in 
mitochondria (Zsigmond et al., 2008) are particularly important cellular processes necessary for plant growth and survival under stressful and normal growth conditions. Therefore, gene expression affecting photosynthesis and energy metabolism in chloroplasts and mitochondria should be tightly regulated for plant growth and survival under stress conditions.

Expression of genes in chloroplasts and mitochondria is regulated mainly at posttranscriptional levels, including RNA processing, intron splicing, RNA editing, RNA turnover, and translational control (del Campo, 2009; Hammani and Giegé, 2014; Sun and Guo, 2016). Although the genomes of chloroplast and mitochondrion harbor less than 150 genes, more than 3,000 and 2,000 nucleus-encoded proteins are transported to the chloroplast and mitochondrion, respectively, and play essential roles in posttranscriptional RNA metabolism in cellular organelles (Millar et al., 2006; Nott et al., 2006; Pesaresi et al., 2007; del Campo, 2009). Therefore, fine-tuning communications between chloroplasts or mitochondria and the nucleus via anterograde signaling and retrograde signaling is essential for organellar gene expression, biogenesis, and function (Zsigmond et al., 2008; del Campo, 2009; Sun and Guo, 2016). Regulation of RNA metabolism in chloroplasts and mitochondria mediated by nucleus-encoded proteins is important for plants to adapt to deleterious biotic and abiotic stresses (Simpson and Filipowicz, 1996; Meierhoff et al., 2003; Williams and Barkan, 2003; Rocak and Linder, 2004; Floris et al., 2009). Many recent studies have demonstrated that diverse RNA-binding proteins (RBPs) play central roles in plant growth, development, and stress responses (Lorković, 2009; Cook et al., 2011; Ambrosone et al., 2012; Kang et al., 2013; Lee and Kang, 2016). Considering that organellar RNA metabolism and gene expression largely depend on nucleusencoded RBPs, it is imperative to understand the functions of nucleus-encoded organellar RBPs to provide us deeper insights into how plants respond to diverse environmental stresses. Among RBPs are DEAD-box RNA helicases (RHs) that can assist the formation of functional mature RNAs in chloroplasts and mitochondria (Cordin et al., 2006; Kohler et al., 2010). In this review, we will focus on the emerging roles of nucleusencoded chloroplast- or mitochondria-targeted DEAD-box RHs in organellar RNA metabolism and plant responses to diverse abiotic stresses.

\section{STRUCTURAL FEATURES OF DEAD-BOX RNA HELICASES}

RHs are enzymes implicated in a number of cellular processes involving alteration of RNA structures. Based on their shared sequence motifs, RHs are classified into six super families (SF1-SF6). Superfamily II (SF2), the largest helicase family, is mainly composed of DEAD-box RHs (Gorbalenya and Koonin, 1993; Fairman-Williams et al., 2010). Unwinding of doublestranded nucleic acids (DNAs and RNAs) requires energy. Hence, all DEAD-box RHs contain a nucleoside triphosphate (NTP) binding motif. Besides this NTP motif, DEAD-box RHs harbor eight motifs called Q, I, Ia, Ib, II, III, IV, V, and VI (Caruthers and McKay, 2002; Silverman et al., 2003; Tuteja and Tuteja, 2004; Kwong et al., 2005; Singleton et al., 2007) falling under two helicase domains: domain I and domain II. They span over a conserved core region of 400-700 amino acids (de la Cruz et al., 1999; Rocak and Linder, 2004; Figure 1). Each motif has specific function for helicase activity. The Q-motif is the most recently discovered motif. It has highly conserved glutamine residue and regulates ATP binding and hydrolysis (Tanner, 2003; Tanner et al., 2003). Motif I (AxxGxGKT) forms a loop structure (P loop) that accommodates ATP and facilitates interactions with $\mathrm{Mg}^{2+}$ ions (Tanner and Linder, 2001). Motif Ia forms the groove for facilitating single-stranded DNA/RNA binding (Velankar et al., 1999). Motif II contains a so-called “DEAD” (Asp-Glu-Ala-Asp) box. Its highly conserved first Asp (D) residue interacts with $\mathrm{Mg}^{2+}$ ion which is required for NTP binding (Gorbalenya and Koonin, 1989). On the basis of sequence alteration in motif II, SF2 members are classified into three sub-groups: Ski2, DEADbox, and DEAH-box. Both DEAD-box and DEAH-box RHs have close sequence similarities except alterations in conserved amino acid sequences at motif II (Tanner and Linder, 2001). Motif III (SAT) is required for NTPase and helicase activities and performs the unwinding of RNA (Pause and Sonenberg, 1992). Motif VI (HxxGRxxR) is the third most conserved segment (Gorbalenya and Koonin, 1989). It is part of the ATP-binding cleft and also involved in coupling between helicase and NTPase activities of the protein (Pause and Sonenberg, 1992). The structures of RHs indicate that the remaining motifs (Ib, IV, and V) are probably involved in RNA binding (Rocak and Linder, 2004), although biochemical data are still lacking.

\section{OCCURRENCE OF DEAD-BOX RHS IN THE CHLOROPLASTS AND MITOCHONDRIA OF PLANTS}

Although numerous reports have demonstrated that the plant genome encodes a large number of RHs which play significant roles in the regulation of various cellular metabolic pathways, their occurrence and functions in chloroplasts and mitochondria have not been well-documented yet. The genomes of Caenorhabditis elegans and Drosophila melanogaster encode 30 and 34 DEAD-box RHs, respectively, which are only half of the number of DEAD-box RHs found in plants (Boudet et al., 2001). In Arabidopsis thaliana, at least $120 \mathrm{RH}$ members have been predicted using TAIR database ${ }^{1}$ (Mingam et al., 2004; Umate et al., 2010), and 58 DEAD-box RHs have been identified so far (Aubourg et al., 1999; Boudet et al., 2001; Zybailov et al., 2008). Among the identified 58 DEAD-box RHs, 10 DEADbox RHs target chloroplasts and eight DEAD-box RHs are localized in the mitochondria (Table 1). The genome of rice (Oryza sativa) harbors more than 60 genes encoding DEAD-box RHs (Umate et al., 2010). Among the identified rice DEAD-box RHs, one RH, OsABP, has been confirmed to be localized in chloroplasts (Macovei et al., 2012), and one RH, OsSUV3, has been confirmed to be localized in mitochondria (Tuteja et al.,

${ }^{1}$ http://www.arabidopsis.org 


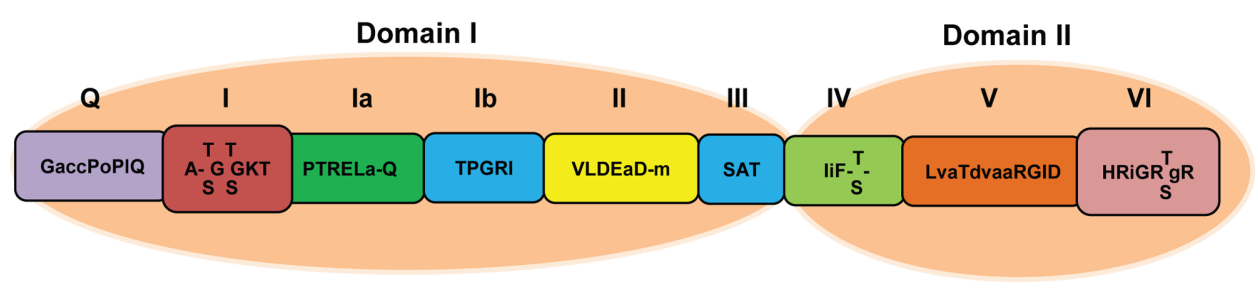

FIGURE 1 | Schematic representation of the domain structure of SF2 family DEAD-box RH. The Q, I, la, Ib, II, and III motifs are included in domain I, and motifs IV, V, and VI are in domain II. Capital letters represent highly conserved amino acid sequences with $>80 \%$ homology while small letters indicate less conserved amino acid sequences with $50-80 \%$ homology.

2013). To date, functions of only one DEAD-box RH have been determined in the chloroplasts of tobacco (Nicotiana tabacum), barely (Hordeum vulgare), and maize (Zea mays) (Table 1).

In addition to these previously identified DEAD-box RHs, our search for DEAD-box RHs harboring potential target sequences for chloroplasts or mitochondria localization revealed more potential chloroplast- or mitochondria-targeted DEADbox RHs. Using web-based software and database $e^{2,3,4,5,6}$, we identified 12 DEAD-box RHs with putative chloroplast transit peptide (cTP) sequence and four DEAD-box RHs with putative mitochondrial targeting sequences in rice. We also identified seven DEAD-box RHs containing cTP sequences and five DEADbox RHs harboring mitochondrial targeting sequences in maize. In addition, we found eight DEAD-box RHs with potential cTP sequences and seven DEAD-box RHs having mitochondrial targeting sequences in wheat (Triticum aestivum; Table 2). These findings suggest that approximately 7-12 DEAD-box RHs and 4-7 DEAD-box RHs are targeted to the chloroplast and mitochondria, respectively, which are much larger numbers than previously reported, indicating that DEAD-box RHs might play significant roles in gene expression regulation and functions in chloroplasts and mitochondria.

\section{DEAD-BOX RHs PLAY CRUCIAL ROLES IN RNA METABOLISM IN CHLOROPLASTS AND MITOCHONDRIA}

Increasing numbers of recent reports have pointed to the importance of DEAD-box RHs in the regulation of RNA metabolism in chloroplasts and mitochondria (Figure 2). Arabidopsis RH3, RH22, and ISE2 are involved in the splicing of group I and II introns and the processing of $23 \mathrm{~S}$ and $16 \mathrm{~S}$ rRNAs in chloroplasts to help assemble the 50S ribosomal subunit (Chi et al., 2012; Kanai et al., 2013; Gu et al., 2014; Carlotto et al., 2016). In particular, Arabidopsis RH39 has been found to introduce a hidden break in chloroplast 23S rRNA, which is an essential process for the maturation of $23 \mathrm{~S}$ rRNA

\footnotetext{
${ }^{2}$ http://plants.ensembl.org

${ }^{3}$ http://www.ncbi.nlm.nih.gov

${ }^{4} \mathrm{http}: / /$ archive.plants.ensembl.org/Triticum_aestivum/Info/Index

${ }^{5} \mathrm{http}: / /$ ensembl.gramene.org/Triticum_aestivum/Info/Index

${ }^{6} \mathrm{http}: / /$ ensembl.gramene.org/Zea_mays/Info/Index
}

(Nishimura et al., 2010). A recent report has demonstrated that chloroplast-targeted $\mathrm{ZmRH} 3$ is involved in rRNA biogenesis and the splicing of chloroplast introns in maize (Asakura et al., 2012). Several mitochondria-localized DEAD-box RHs such as ABO6, PHM1, and PHM2 can regulate the splicing of introncontaining genes in Arabidopsis (Matthes et al., 2007; Kohler et al., 2010; He et al., 2012). Mitochondria-localized AtSUV3 and OsSUV3 are involved in mRNA processing and RNA degradation to regulate gene expression in Arabidopsis and rice, respectively (Gagliardia et al., 1999; Tuteja et al., 2013). A mitochondrial MDDX28 is involved in mRNA transport, which is important for communications between the nucleus and mitochondria (Valgardsdottir et al., 2001). Recently, several chloroplast-localized DEAD-box RHs (such as RH58, RH47, RH26, RH50, RH41, and RH52) and mitochondria-targeted DEAD-box RHs (such as RH33 and RH31) have been shown to regulate transcription in response to multiple abiotic stresses (Umate et al., 2010). Moreover, chloroplast-targeted AtRH26 and AtRH41 and mitochondria-localized DEAD-box RHs, AtRH9, AtRH33, and AtRH31 have been found to interact with proteins involved in the formation of replication complex in turnip mosaic virus (Li et al., 2016). All these reports emphasize that DEADbox RHs are essential for RNA metabolism in chloroplasts and mitochondria.

Although the functions of many DEAD-box RHs in chloroplasts or mitochondria await further experimental verification, their possible cellular roles can be inferred from the studies on nuclear RHs in plants. Two rice DEAD-box RHs, OsRH2 and OsRH34, are essential components of exon junction complex (Huang et al., 2016), and rice TOGR1 (for thermotolerant growth required 1) is involved in pre-rRNA homeostasis (Wang et al., 2016). Arabidopsis DEAD-box RHs (AtRH7, AtRH36, and AtRH57) and maize ZmDRH1 play essential roles in rRNA processing (Huang et al., 2010; Hsu et al., 2014; Liu et al., 2016). Notably, the CARPEL FACTORY, an Arabidopsis DEAD-box RH, is involved in the biogenesis of microRNAs (miRNAs; Park et al., 2002) and nuclear DEAD-box RHs play a crucial role in the metabolism of aberrant and silencing RNAs (reviewed in Linder and Owttrim, 2009). Considering that chloroplasts and mitochondria also contain small non-coding RNAs (ncRNAs) and miRNAs (Lung et al., 2006; reviewed in Hotto et al., 2012), it is of keen interest to determine whether DEAD-box RHs are involved in the processing and biogenesis of ncRNAs or miRNAs in chloroplasts and mitochondria. 
TABLE 1 | List of DEAD-box RHs associated with RNA metabolism in chloroplasts or mitochondria and stress responses in various plants.

\begin{tabular}{|c|c|c|c|c|}
\hline Plant & Localization & Gene & Functions & Reference \\
\hline \multirow[t]{14}{*}{ A. thaliana } & Chloroplast & $\mathrm{RH} 22$ & $\begin{array}{l}\text { mRNA accumulation during seed growth and } \\
\text { development, biogenesis of chloroplast ribosomes, } \\
\text { accumulation of TuMV CP }\end{array}$ & $\begin{array}{l}\text { Chi et al., 2012; } \\
\text { Kanai et al., } 2013\end{array}$ \\
\hline & & $\mathrm{RH} 39$ & Maturation of $23 \mathrm{~S}$ rRNA in chloroplasts & Nishimura et al., 2010 \\
\hline & & AtRH3 & Intron splicing, rRNA processing, ABA response & $\begin{array}{l}\text { Lee et al., 2013; } \\
\text { Asakura et al., 2012; } \\
\text { Gu et al., } 2014\end{array}$ \\
\hline & & AtRH26 & $\begin{array}{l}\text { Participates in TuMV replication complex, expression } \\
\text { modulated by abiotic stresses }\end{array}$ & $\begin{array}{l}\text { Zybailov et al., 2008; } \\
\text { Mingam et al., 2004; } \\
\text { Umate et al., 2010; } \\
\text { Li et al., } 2016\end{array}$ \\
\hline & & AtRH41 & Expression modulated by abiotic stresses & $\begin{array}{l}\text { Umate et al., 2010; } \\
\text { Li et al., } 2016\end{array}$ \\
\hline & & ISE2 & Group II intron splicing, plasmodesmata regulation & Carlotto et al., 2016 \\
\hline & & $\begin{array}{l}\text { AtRH47 } \\
\text { AtRH50 } \\
\text { AtRH52 } \\
\text { AtRH58 }\end{array}$ & Expression modulated by abiotic stresses & $\begin{array}{l}\text { Zybailov et al., 2008; } \\
\text { Mingam et al., 2004; } \\
\text { Umate et al., } 2010\end{array}$ \\
\hline & Mitochondria & $\begin{array}{l}\mathrm{PMHI} \\
(\mathrm{AtRH})\end{array}$ & $\begin{array}{l}\text { Group II intron splicing } \\
\text { Seed germination under salt stress } \\
\text { Participates in TuMV replication complex }\end{array}$ & $\begin{array}{l}\text { Matthes et al., } 2007 \\
\text { Kim et al., } 2008 \\
\text { Kohler et al., } 2010 \\
\text { Li et al., } 2016\end{array}$ \\
\hline & & $\mathrm{PMH} 2$ & Group II intron splicing & $\begin{array}{l}\text { Matthes et al., 2007; } \\
\text { Kohler et al., } 2010\end{array}$ \\
\hline & & $\begin{array}{l}\text { AtRH31 } \\
\text { AtRH33 }\end{array}$ & $\begin{array}{l}\text { Expression modulated by abiotic stresses } \\
\text { Participates in TuMV replication complex }\end{array}$ & $\begin{array}{l}\text { Umate et al., 2010; } \\
\text { Li et al., } 2016\end{array}$ \\
\hline & & ABO6 & Group I intron splicing, ABA and auxin response & He et al., 2012 \\
\hline & & PLT1 & Regulation of root meristem activity under ABA & Yang et al., 2014 \\
\hline & & MDDX28 & $\begin{array}{l}\text { Communications between the nucleus and } \\
\text { mitochondria }\end{array}$ & Valgardsdottir et al., 2001 \\
\hline & & AtSUV3 & $\begin{array}{l}\text { ATPases activity, mitochondrial mRNA } \\
\text { processing/degradation }\end{array}$ & Gagliardia et al., 1999 \\
\hline \multirow[t]{2}{*}{ O. sativa } & Chloroplast & OsABP & Regulation of signal transduction, stress response & Macovei et al., 2012 \\
\hline & Mitochondria & OsSUV3 & RNA surveillance and turn over, salinity tolerance & $\begin{array}{l}\text { Tuteja et al., 2013; } \\
\text { Sahoo et al., } 2014\end{array}$ \\
\hline N. tabacum & Chloroplast & VDL & Early differentiation of chloroplasts & Wang et al., 2000 \\
\hline Z. mays & & $\mathrm{ZmRH} 3$ & Intron splicing, rRNA processing & Asakura et al., 2012 \\
\hline H. vulgare & & HVD1 & Expression modulated by salt stress & Nakamura et al., 2004 \\
\hline
\end{tabular}

\section{CHLOROPLAST- OR MITOCHONDRIA-TARGETED DEAD-BOX RHS HAVE DIVERSE ROLES IN PLANT GROWTH AND ABIOTIC STRESS RESPONSES}

Several recent studies have demonstrated that chloroplastor mitochondria-targeted DEAD-box RHs play essential roles in plant growth and development under normal conditions (Figure 2). A chloroplast-targeted RH, INCREASED SIZE EXCLUSION LIMIT 2, is required for group II intron splicing and is involved in chloroplast pigmentation and plasmodesmata regulation during embryogenesis of Arabidopsis (Carlotto et al., 2016). A tobacco DEAD-box RH, VDL (for variegated and distorted leaf), is involved in early chloroplast maturation and regulates flower and root growth (Wang et al., 2000).
Several mitochondria-localized RHs, PMHI (AtRH9), PMHII, and $\mathrm{ABO} 6$, regulate seed germination in Arabidopsis (Kim et al., 2008; Kohler et al., 2010; He et al., 2012). These results clearly show that chloroplast- or mitochondria-targeted DEAD-box RHs play important roles in plant growth and development. As nuclear DEAD-box RHs are involved in regulating programmed cell death in rice (Li et al., 2011) and two DEAD-box RHs in rice, OsRH2 and OsRH34, are necessary for pollen and seed development (Huang et al., 2016), further determination of the functions of chloroplast or mitochondrial DEAD-box RHs in plant development is necessary.

Although the functions of chloroplast- or mitochondriatargeted DEAD-box RHs in plant growth and development are known for only a few cases, potential roles of DEAD-box RHs in abiotic stresses are increasingly being discovered (Table $\mathbf{1}$ and Figure 2). Chloroplast-localized RH3 (Gu et al., 2014) and mitochondria-targeted PMHI (AtRH9; Matthes et al., 2007; Kim 
TABLE 2 | List of predicted chloroplast- or mitochondria-targeted DEAD-box RHs and stress-responsive expression patterns.

\begin{tabular}{|c|c|c|c|c|c|}
\hline \multirow[t]{2}{*}{ Plant } & \multirow[t]{2}{*}{ Localization $^{\#}$} & \multirow[t]{2}{*}{ Gene ID } & \multicolumn{3}{|c|}{ Modulation* } \\
\hline & & & Drought & Cold & Salt \\
\hline & Mitochondria & $\begin{array}{c}\text { Os01g10050 (OsRH20), Os03g19530 (RH24) } \\
\text { Os07g45360 (RH57) }\end{array}$ & & Down-regulated & \\
\hline & & Os05g01990 (RH17) & & Up-regulated & \\
\hline \multirow{3}{*}{ Z. mays } & & & Drought & Cold & Heat \\
\hline & Mitochondria & $\begin{array}{l}\text { GRMZM2G099253 (ZmRH36), GRMZM2G143246 (ZmRH20) } \\
\text { GRMZM5G857708 (ZmRH14), GRMZM2G346278 (ZmRH17) }\end{array}$ & & Down-regulated & \\
\hline & & GRMZM2G362850 (ZmRH30) & & Up-regulated & \\
\hline \multirow[t]{3}{*}{ T. aestivum } & Chloroplast & $\begin{array}{l}\text { TRIAE_CS42_5BL_TGACv1_405472_AA1328050 (RH3) } \\
\text { TRIAE_CS42_5AL_TGACv1_378036_AA1250890 (RH29) }\end{array}$ & & Down-regulated & \\
\hline & & $\begin{array}{l}\text { TRIAE_CS42_5BL_TGACv1_405071_AA1319340 (RH7) } \\
\text { TRIAE_CS42_2DL_TGACV1_162281_AA0562360 (RH13) } \\
\text { TRIAE_CS42_2AS_TGACV1_112416_AA0337680 (RH36) } \\
\text { TRIAE_CS42_4DS_TGACV1_362163_AA1177330 (RH16) } \\
\text { TRIAE_CS42_3DL_TGACV1_251106_AA0877450 (RH58) } \\
\text { TRIAE_CS42_5AL_TGACV1_377240_AA1245280 (RH28) }\end{array}$ & & No data available & \\
\hline & Mitochondria & $\begin{array}{l}\text { TRIAE_CS42_4AS_TGACV1_307021_AA1016210 (RH24) } \\
\text { TRIAE_CS42_3AS_TGACV1_211081_AA0684720 (RH20) } \\
\text { TRIAE_CS42_6AL_TGACV1_473376_AA1530620 (RH47) } \\
\text { TRIAE_CS42_4DL_TGACV1_344498_AA1147590 (RH17) } \\
\text { TRIAE_CS42_4DL_TGACV1_342854_AA1123970 (RH50) } \\
\text { TRIAE_CS42_3B_TGACV1_221078_AA0729540 (RH39) } \\
\text { TRIAE_CS42_5DL_TGACV1_433272_AA1407810 (RH22) }\end{array}$ & & No data available & \\
\hline
\end{tabular}

\begin{abstract}
\#Ensembl Plants (http://plants.ensembl.org) and NCBI (https://www.ncbi.nlm.nih.gov) were used to search for DEAD-box RHs. Cellular localization of proteins was predicted using TargetP 1.1 Server (http://www.cbs.dtu.dk/services/TargetP), ChloroP 1.1 Server (http://www.cbs.dtu.dk/services/ChloroP), and Predotar Server (https://urgi.versailles.inra.fr/predotar).

*GENEVESTIGATOR (https://genevestigator.com) and BAR (www.bar.utoronto.ca) were used to analyze the stress-responsive expression patterns of each DEADbox RH.
\end{abstract}

et al., 2008; Kohler et al., 2010) have been found to confer freezing tolerance in Arabidopsis. A chloroplast-localized HVD1 has been found to be up-regulated by cold and salt stress and affected photosynthetic activity under stress in barley (Nakamura et al., 2004). A chloroplast-localized OsABP is involved in the response of rice to diverse abiotic stresses (Macovei et al., 2012). Several studies have demonstrated that mitochondrialocalized rice OsSUV3 and Arabidopsis AtOsSUV3 can regulate the expression of various stress-induced genes and confer plants tolerance to salt stress (Gagliardia et al., 1999; Tuteja et al., 2013; Sahoo et al., 2014). Recently, mitochondrial PLT1 (PLETHORA1) and ABO6 (ABA overly sensitive) have been found to play important roles in the regulation of primary root growth and root meristem activity by modulating ABA and auxin signaling (He et al., 2012; Yang et al., 2014). A chloroplast-targeted RH3 is reported to be essential for carbon fixation and the maintenance of ABA level in Arabidopsis under environmental stresses (Lee et al., 2013).

In addition to these already-verified chloroplast- or mitochondria-targeted DEAD-box RHs, our analysis using GENEVESTIGATOR $^{7}$ and Bio-Analytic Resource for Plant Biology $^{8}$ servers showed that the expression of potential chloroplast- or mitochondria-targeted DEAD-box RHs found in rice, maize, and wheat was high modulated by various abiotic stresses (Table 2), implying that more DEAD-box RHs in chloroplasts or mitochondria might be involved in abiotic stress responses. Interestingly, the expression of majority of chloroplast- or mitochondria-targeted DEAD box-RHs in rice, maize, and wheat is down-regulated under diverse abiotic

\footnotetext{
${ }^{7}$ https://genevestigator.com

${ }^{8}$ http://www.bar.utoronto.ca
} 


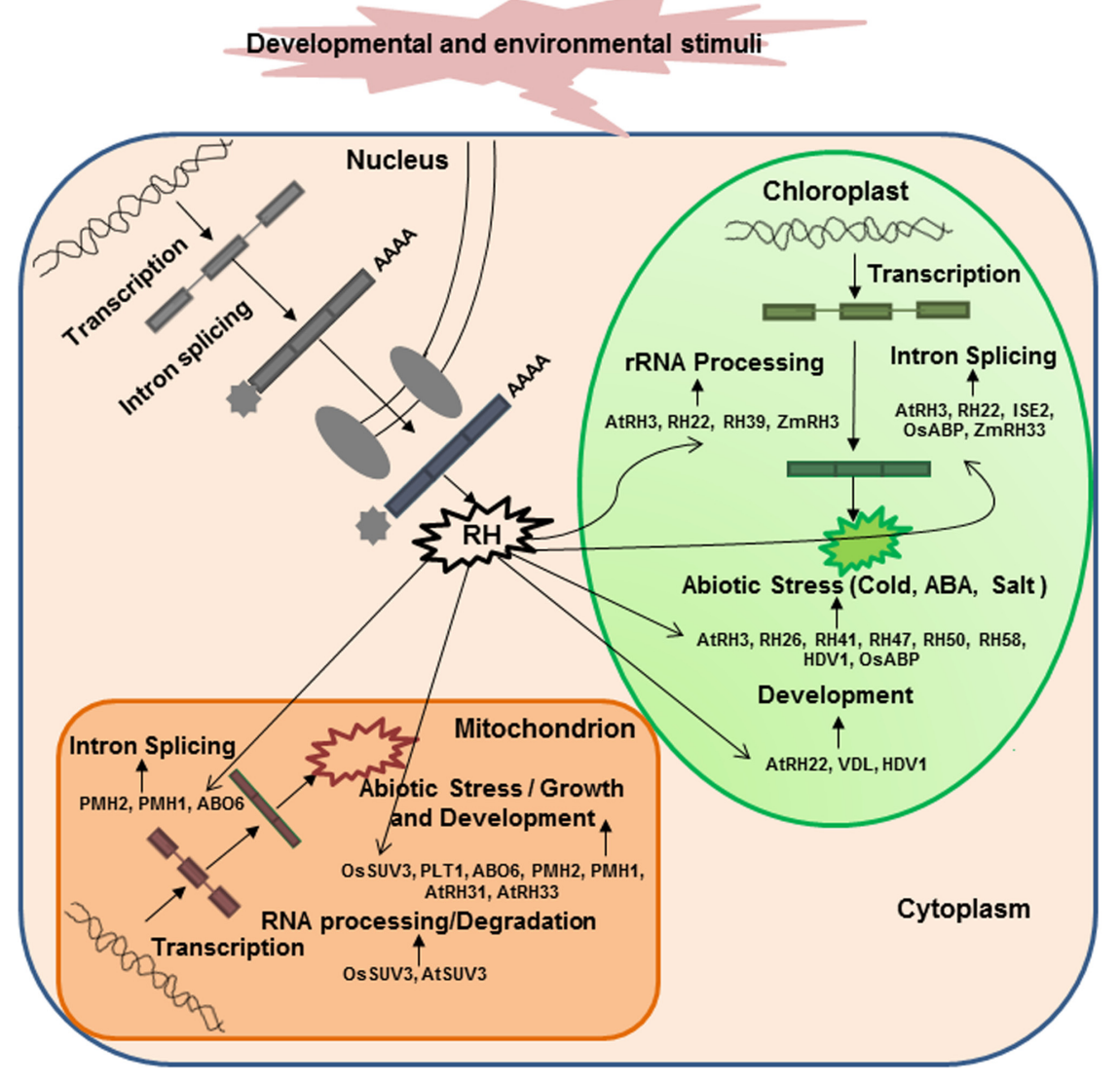

FIGURE 2 | Cellular functions of diverse DEAD-box RHs involved in RNA metabolism in chloroplasts or mitochondria. A variety of nucleus-encoded RHs are targeted to chloroplasts or mitochondria and play essential roles in RNA processing, intron splicing, and translation, crucial for organellar biogenesis, function, and stress responses. Examples of the experimentally verified DEAD-box RHs that play unique roles in chloroplasts and mitochondria are shown in parenthesis. The functions and cellular roles of each $\mathrm{RH}$ are described in Table $\mathbf{1 .}$

stresses (Table 2). Although the physiological significance of such stress-responsive expression patterns of DEAD-box RHs remains unclear, these findings suggest that a large number of nucleus-encoded chloroplast- or mitochondria-targeted DEAD-box RHs might be involved in plant responses to diverse abiotic stresses. Considering that photosynthesis in chloroplasts functions as a global sensor of abiotic stresses (Biswal et al., 2011) and that expression of genes in chloroplasts is mainly regulated at posttranscriptional RNA metabolism (del Campo, 2009; Stern et al., 2010), it is interesting to determine how DEAD-box RHs affect the processing, splicing, and decay of chloroplast transcripts involved in photosynthesis, which will provide further insights into the importance of DEAD-box RHs in plant growth and survival under stress conditions.

\section{CONCLUDING REMARKS AND FUTURE PERSPECTIVES}

Although recent progress on the analysis of plant genomes and proteomes has revealed the presence of a large number of DEAD-box RHs targeted to chloroplasts or mitochondria, cellular roles of DEAD-box RHs in organellar RNA metabolism and function remain unclear. It is evident that DEAD-box RHs targeted to either chloroplasts or mitochondria is crucial for the regulation of gene expression and RNA metabolism in these cellular organelles. However, more analyses are needed to determine the functions of each DEAD-box RH family member. Considering that communications between the nucleus and chloroplasts or mitochondria via anterograde and retrograde signaling are essential for organellar gene expression, biogenesis, and function (Zsigmond et al., 2008; del Campo, 2009; Sun and Guo, 2016), it would be of great interest to determine whether chloroplast- or mitochondria-targeted DEAD-box RHs can affect the expression of nuclear genes under stress conditions. In addition, it is necessary to determine the mechanistic roles of DEAD-box RHs in organellar RNA metabolism. Given that several RHs function as RNA chaperones to aid RNA folding via structural rearrangement of substrate RNAs (Kang et al., 2013; Lee and Kang, 2016), it is likely that these chloroplastor mitochondria-targeted DEAD-box RHs might also function as RNA chaperones in organellar RNA metabolism. Major future tasks should be focused on identifying RNA targets and understanding how DEAD-box RHs recognize substrate 
RNAs to regulate posttranscriptional RNA metabolism in cellular organelles. Such studies will provide further insights into the importance of DEAD-box RHs targeted to chloroplasts and mitochondria in plant growth and survival.

\section{AUTHOR CONTRIBUTIONS}

GN and HK contributed equally writing the review.

\section{REFERENCES}

Ambrosone, A., Costa, A., Leone, A., and Grillo, S. (2012). Beyond transcription: RNA-binding proteins as emerging regulators of plant response to environmental constraints. Plant Sci. 182, 12-18. doi: 10.1016/j.plantsci. 2011.02.004

Asakura, Y., Galarneau, E., Watkins, K. P., Barkan, A., and van Wijk, K. J. (2012). Chloroplast RH3 DEAD-box RNA helicases in Zea mays and Arabidopsis thaliana function in splicing of specific group II introns and affect chloroplast ribosome. Plant Physiol. 159, 961-974. doi: 10.1104/pp.112.197525

Ashraf, M., and Harris, P. J. C. (2013). Photosynthesis under stressful environments: an overview. Photosynthetica 51, 163-190. doi: 10.1007/s11099013-0021-6

Aubourg, S., Kreis, M., and Lecharny, A. (1999). The DEAD box RNA helicase family in Arabidopsis thaliana. Nucleic Acids Res. 27, 628-636. doi: 10.1093/nar/ 27.2.628

Biswal, B., Joshi, P. N., Raval, M. K., and Biswal, U. C. (2011). Photosynthesis, a global sensor of environmental stress in green plants: stress signaling and adaptation. Curr. Sci. 101, 47-56. doi: 10.1371/journal.pone.0032124

Boudet, N., Aubourg, S., Toffano-Nioche, C., Kreis, M., and Lecharny, A. (2001). Evolution of intron/exon structure of DEAD helicase family genes in Arabidopsis, Caenorhabditis, and Drosophila. Genome Res. 11, 2101-2114. doi: 10.1101/gr.200801

Carlotto, N., Wirth, S., Furman, N., Ferreyra-Solari, N., Ariel, F., Crespi, M., et al. (2016). The chloroplastic DEVH-box RNA helicase INCREASED SIZE EXCLUSION LIMIT 2 involved in plasmodesmata regulation is required for group II intron splicing. Plant Cell Environ. 39, 165-173. doi: 10.1111/pce.12603

Caruthers, J. M., and McKay, D. B. (2002). Helicase structure and mechanism. Curr. Opin. Struct. Biol. 12, 123-133. doi: 10.1016/s0959-440x(02)00298-1

Chi, W., He, B., Mao, J., Li, Q., Ma, J., Ji, D., et al. (2012). The function of RH22, a DEAD RNA helicase, in the biogenesis of the 50S ribosomal subunits of Arabidopsis chloroplasts. Plant Physiol. 158, 693-707. doi: 10.1104/pp.111. 186775

Cook, K. B., Kazan, H., Zuberi, K., Morris, Q., and Hughes, T. R. (2011). RBPDB: a database of RNA-binding specificities. Nucleic Acids Res. 39, D301-D308. doi: 10.1093/nar/gkq1069

Cordin, O., Banroques, J., Tanner, N. K., and Linder, P. (2006). The DEAD-box protein family of RNA helicases. Gene 367, 17-37. doi: 10.1016/j.gene.2005. 10.019

de la Cruz, J., Kressler, D., and Linder, P. (1999). Unwinding RNA in Saccharomyces cerevisiae: DEAD box proteins and related families. Trends Biochem. Sci. 24, 192-198. doi: 10.1016/s0968-0004(99)01376-6

del Campo, E. M. (2009). Post-transcriptional control of chloroplast gene expression. Gene Regul. Syst. Biol. 3, 31-47.

Fairman-Williams, M. E., Guenther, U. P., and Jankowsky, E. (2010). SF1 and SF2 helicases: family matters. Curr. Opin. Struct. Biol. 20, 313-324. doi: 10.1016/j. sbi.2010.03.011

Floris, M., Mahgoub, H., Lanet, E., Robaglia, C., and Menand, B. (2009). Posttranscriptional regulation of gene expression in plants during abiotic stress. Int. J. Mol. Sci. 10, 3168-3185. doi: 10.1101/gad.11.14.1864

Gagliardia, D., Kuhn, J., Spadinger, U., Brennicke, A., Leaver, C. J., and Binder, S. (1999). An RNA helicase (AtSUV3) is present in Arabidopsis thaliana mitochondria. FEBS Lett. 458, 337-342. doi: 10.1016/s0014-5793(99)01168-0

\section{FUNDING}

This work was supported by a grant from the Next-Generation BioGreen21 Program (PJ01105401), Rural Development Administration, Republic of Korea, and by a grant from the Mid-career Researcher Program through the National Research Foundation of Korea funded by the Ministry of Science, ICT and Future Planning (NRF-2016R1A2B4009172), Republic of Korea.

Gorbalenya, A. E., and Koonin, E. V. (1989). Viral proteins containing the purine NTP-binding sequence pattern. Nucleic Acids Res. 17, 8413-8440. doi: 10.1093/ nar/gki578

Gorbalenya, A. E., and Koonin, E. V. (1993). Helicases: amino acids sequence comparisons and structure-function relationship. Curr. Opin. Struct. Biol. 3, 419-429. doi: 10.1016/s0959-440x(05)80116-2

Gu, L., Xu, T., Lee, K., Lee, K. H., and Kang, H. (2014). A chloroplastlocalized DEAD-box RNA helicase AtRH3 is essential for intron splicing and plays an important role in the growth and stress response in Arabidopsis thaliana. Plant Physiol. Biochem. 82, 309-318. doi: 10.1016/j.plaphy.2014. 07.006

Hammani, K., and Giegé, P. (2014). RNA metabolism in plant mitochondria. Trends Plant Sci. 19, 380-389. doi: 10.1016/j.tplants.2013.12.008

He, J., Duan, Y., Hua, D., Fan, G., Wang, L., and Liu, Y. (2012). DEXH box RNA helicase-mediated mitochondrial reactive oxygen species production in Arabidopsis mediates crosstalk between abscisic acid and auxin signaling. Plant Cell 24, 1815-1833. doi: 10.1105/tpc.112.098707

Hotto, A. M., Germain, A., and Stern, D. B. (2012). Plastid non-coding RNAs: emerging candidates for gene regulation. Trends Plant Sci. 17, 737-744. doi: 10.1016/j.tplants.2012.08.002

Hsu, Y. F., Chen, Y. C., Hsiao, Y. C., Wang, B. J., Lin, S. Y., Cheng, W. H., et al. (2014). AtRH57, a DEAD-box RNA helicase, is involved in feedback inhibition of glucose mediated abscisic acid accumulation during seedling development and additively affects pre-ribosomal RNA processing with high glucose. Plant J. 77, 119-135. doi: 10.1111/tpj.12371

Huang, C. K., Huang, L. F., Huang, J. J., Wu, S. J., Yeh, C. H., and Lu, C. A. (2010). A DEAD- box protein, AtRH36, is essential for female gametophyte development and is involved in rRNA biogenesis in Arabidopsis. Plant Cell Physiol. 51, 694-706. doi: 10.1093/pcp/pcq045

Huang, C. K., Si, Y. S., Chen, Y. F., Huang, T. S., and Lu, C. A. (2016). Two highly similar DEAD-box proteins, OsRH2 and OsRH34, homologous to eukaryotic initiation factor 4AIII, play roles of the exon junction complex in regulating growth and development in rice. BMC Plant Biol. 16:84. doi: 10.1186/s12870016-0769-5

Kanai, M., Hayashi, M., Kondo, M., and Nishimura, M. (2013). The plastidic DEAD-box RNA helicase 22, HS3, is essential for plastid functions both in seed development and in seedling growth. Plant Cell Physiol. 54, 1431-1440. doi: $10.1093 / \mathrm{pcp} / \mathrm{pct} 091$

Kang, H., Park, S. J., and Kwak, K. J. (2013). Plant RNA chaperones in stress response. Trends Plant Sci. 18, 100-106. doi: 10.1016/j.tplants.2012.08.004

Kim, J. S., Kim, K. A., Oh, T. R., Park, C. M., and Kang, H. (2008). Functional characterization of DEAD-box RNA helicases in Arabidopsis thaliana under abiotic stress conditions. Plant Cell Physiol. 49, 1563-1571. doi: 10.1093/pcp/ pcn 125

Kohler, D., Schmidt-Gattung, S., and Binder, S. (2010). The DEAD-box protein $\mathrm{PMH} 2$ is required for efficient group II intron splicing in mitochondria of Arabidopsis thaliana. Plant Mol. Biol. 72, 459-467. doi: 10.1007/s11103-0099584-9

Komatsu, S., and Hossain, Z. (2013). Organ-specific proteome analysis for identification of abiotic stress response mechanism in crop. Front. Plant Sci. 4:71. doi: 10.3389/fpls.2013.00071

Kwong, A. D., Rao, B. G., and Jeang, K. T. (2005). Viral and cellular RNA helicases as antiviral targets. Nat. Rev. Drug Discov. 4, 845-853. doi: 10.1038/nrd1853 
Lee, K., and Kang, H. (2016). Emerging roles of RNA-binding proteins in plant growth, development, and stress responses. Mol. Cells 39, 179-185. doi: 10.14348/molcells.2016.2359

Lee, K. H., Park, J., Williams, D. S., Xiong, Y., Hwang, I., and Kang, B. H. (2013). Defective chloroplast development inhibits maintenance of normal levels of abscisic acid in a mutant of the Arabidopsis RH3 DEAD-box protein during early post-germination growth. Plant J. 73, 720-732. doi: 10.1111/tpj.12055

Li, X., Gao, X., Wei, Y., Deng, L., Ouyang, Y., Chen, G., et al. (2011). Rice APOPTOSIS INHIBITOR5 coupled with two DEAD-Box adenosine 5' triphosphate-dependent RNA helicases regulates tapetum degeneration. Plant Cell 23, 1416-1434. doi: 10.1105/tpc.110.082636

Li, Y., Xiong, R., Bernards, M., and Wang, A. (2016). Recruitment of Arabidopsis RNA helicase AtRH9 to the viral replication complex by viral replicase to promote turnip mosaic virus replication. Sci. Rep. 6:30297. doi: 10.1038/ srep30297

Linder, P., and Owttrim, G. W. (2009). Plant RNA helicases: linking aberrant and silencing RNA. Trends Plant Sci. 14, 344-352. doi: 10.1016/j.tplants.2009.03.007

Liu, Y., Tabata, D., and Ima, R. (2016). A cold-inducible DEAD-box RNA helicase from Arabidopsis thaliana regulates plant growth and development under low temperature. PLoS ONE 11:e0154040. doi: 10.1371/journal.pone.0154040

Lorković, Z. J. (2009). Role of plant RNA-binding proteins in development, stress response and genome organization. Trends Plant Sci. 14, 229-236. doi: 10.1016/ j.tplants.2009.01.007

Lung, B., Zemann, A., Madej, M. J., Schuelke, M., Techritz, S., Ruf, S., et al. (2006). Identification of small non-coding RNAs from mitochondria and chloroplasts. Nucleic Acids Res. 34, 3842-3852. doi: 10.1093/nar/gkl448

Macovei, A., Vaid, N., Tula, S., and Tuteja, N. (2012). A new DEAD-box helicase ATP-binding protein (OsABP) from rice is responsive to abiotic stress. Plant Signal. Behav. 7, 1138-1143. doi: 10.4161/psb.21343

Matthes, A., Schmidt-Gattung, S., Kohler, D., Forner, J., Wildum, S., Raabe, M., et al. (2007). Two DEAD-box proteins may be part of RNA-dependent highmolecular-mass protein complexes in Arabidopsis mitochondria. Plant Physiol. 145, 1637-1646. doi: 10.1104/pp.107.108076

Meierhoff, K., Felder, S., Nakamura, T., Bechtold, N., and Schuster, G. (2003). HCF152, an Arabidopsis RNA binding pentatricopeptide repeat protein involved in the processing of chloroplast $p s b B-p s b T-p s b H$-petB-petD RNAs. Plant Cell 15, 1480-1495. doi: 10.1105/tpc.010397

Millar, A. H., Whelan, J., and Small, I. (2006). Recent surprises in protein targeting to mitochondria and plastids. Curr. Opin. Plant Biol. 9, 610-615. doi: 10.1016/j. pbi.2006.09.002

Mingam, A., Toffano, N. C., Brunaud, V., Boudet, N., Kreis, M., and Lecharny, A. (2004). DEAD-box RNA helicases in Arabidopsis thaliana, establishing a link between quantitative expression, gene structure and evolution of a family of genes. Plant Biotechnol. J. 2, 401-415. doi: 10.1111/j.1467-7652.2004. 00084.x

Nakamura, T., Muramoto, Y., Yokota, S., Ueda, A., and Takabe, T. (2004). Structural and transcriptional characterization of a salt-responsive gene encoding putative ATP-dependent helicase in barley. Plant Sci. 167, 63-70. doi: $10.1016 /$ j.plantsci.2004.03.001

Nishimura, K., Ashida, H., Ogawa, T., and Yokota, A. (2010). A DEAD box protein is required for formation of a hidden break in Arabidopsis chloroplast $23 \mathrm{~S}$ rRNA. Plant J. 63, 766-777. doi: 10.1111/j.1365-313x.2010.04276.x

Nott, A., Jung, H. S., Koussevitzky, S., and Chory, J. (2006). Plastid-to-nucleus retrograde signaling. Annu. Rev. Plant Biol. 57, 739-759. doi: 10.1146/annurev. arplant.57.032905.105310

Nouri, M. Z., Ali, M., and Komatsu, S. (2015). Abiotic stresses: insight into gene regulation and protein expression in photosynthetic pathways of plants. Int. J. Mol. Sci. 16, 20392-20416. doi: 10.3390/ijms160920392

Park, W., Li, J., Song, R., Messing, J., and Chen, X. (2002). CARPEL FACTORY, a dicer homolog, and HEN1, a novel protein, act in microRNA metabolism in Arabidopsis thaliana. Curr. Biol. 12, 1484-1495. doi: 10.1016/S0960-9822(02) 01017-5

Pause, A., and Sonenberg, N. (1992). Mutational analysis of a DEAD box RNA helicase: the mammalian translation initiation factor eIF-4A. EMBO J. 11, 2643-2654.

Pesaresi, P., Schneider, A., Kleine, T., and Leister, D. (2007). Interorganellar communication. Curr. Opin. Plant Biol. 10, 600-606. doi: 10.1016/j.pbi.2007. 07.007
Ranty, B., Aldon, D., Cotelle, V., Galaud, J. P., Thuleauand, P., and Mazars, C. (2016). Calcium sensors as key hubs in plant responses to biotic and abiotic stresses. Front. Plant Sci. 7:327. doi: 10.3389/fpls.2016.00327

Rocak, S., and Linder, P. (2004). DEAD-box proteins: the driving forces behind RNA metabolism. Nat. Rev. Mol. Cell Biol. 5, 232-241. doi: 10.1038/nrm1335

Sahoo, R. K., Ansari, M. W., Tuteja, R., and Tuteja, N. (2014). OsSUV3 transgenic rice maintains higher endogenous levels of plant hormones that mitigates adverse effects of salinity and sustains crop productivity. Rice 7, 17. doi: 10.1186/ s12284-014-0017-2

Silverman, E., Edwalds-Gilbert, G., and Lin, R. J. (2003). DExD/H-box proteins and their partners: helping RNA helicases unwind. Gene 312, 1-16. doi: 10.1016/ s0378-1119(03)00626-7

Simpson, G. G., and Filipowicz, W. (1996). Splicing of precursors to mRNA in higher plants: mechanism, regulation and sub-nuclear organisation of the spliceosomal machinery. Plant Mol. Biol. 32, 1-41. doi: 10.1007/BF00039375

Singleton, M. R., Dillingham, M. S., and Wigley, D. B. (2007). Structure and mechanism of helicases and nucleic acid translocases. Annu. Rev. Biochem. 76, 23-50. doi: 10.1146/annurev.biochem.76.052305.115300

Stern, D. B., Goldschmidt-Clermont, M., and Hanson, M. R. (2010). Chloroplast RNA metabolism. Annu. Rev. Plant Biol. 61, 125-155. doi: 10.1146/annurevarplant-042809-112242

Sun, A. Z., and Guo, F. Q. (2016). Chloroplast retrograde regulation of heat stress responses in plants. Front. Plant Sci. 7:398. doi: 10.3389/fpls.2016.00398

Tanner, N. K. (2003). The newly identified Q motif of DEAD box helicases is involved in adenine recognition. Cell Cycle 2, 18-19. doi: 10.4161/cc.2.1.296

Tanner, N. K., Cordin, O., Banroques, J., Doère, M., and Linder, P. (2003). The $\mathrm{Q}$ motif. A newly identified motif in DEAD box helicases may regulate ATP binding and hydrolysis. Mol. Cells 11, 127-138. doi: 10.1016/s1097-2765(03) 00006-6

Tanner, N. K., and Linder, P. (2001). DExD/H box RNA helicases: from generic motors to specific dissociation functions. Mol. Cell 8, 251-262. doi: 10.1016/ s1097-2765(01)00329-x

Tuteja, N., Sahoo, R. K., Garg, B., and Tuteja, R. (2013). OsSUV3 dual helicase functions in salinity stress tolerance by maintaining photosynthesis and antioxidant machinery in rice (Oryza sativa L. cv. IR64). Plant J. 76, 115-127. doi: $10.1111 /$ tpj.12277

Tuteja, N., and Tuteja, R. (2004). Unraveling DNA helicases: motif, structure, mechanism and function. Eur. J. Biochem. 271, 1849-1863. doi: 10.1111/j.14321033.2004.04094.x

Umate, P., Tuteja, R., and Tuteja, N. (2010). Genome-wide analysis of helicase gene family from rice and Arabidopsis: a comparison with yeast and human. Plant Mol. Biol. 73, 449-465. doi: 10.1007/s11103-010-9632-5

Valgardsdottir, R., Brede, G., Eide, L. G., Frengen, E., and Prydz, H. (2001). Cloning and characterization of MDDX28, a putative DEAD-box helicase with mitochondrial and nuclear localization. J. Biol. Chem. 276, 32056-32063. doi: 10.1074/jbc.M011629200

Velankar, S. S., Soultanas, P., Dillingham, M. S., Subramanya, H. S., and Wigley, D. B. (1999). Crystal structures of complexes of PcrA DNA helicase with a DNA substrate indicate an inchworm mechanism. Cell 97, 75-84. doi: 10.1016/s00928674(00)80716-3

Wang, D., Qin, B., Li, X., Tang, D., Zhang, Y., Cheng, Z., et al. (2016). Nucleolar DEAD-box RNA helicase TOGR1 regulates thermos-tolerant growth as a prerRNA chaperone in rice. PLoS Genet. 12:e1005844. doi: 10.1371/journal.pgen. 1005844

Wang, Y., Duby, G., Purnelle, B., and Boutry, M. (2000). Tobacco VDL gene encodes a plastid DEAD box RNA helicase and is involved in chloroplast differentiation and plant morphogenesis. Plant Cell 12, 2129-2142. doi: 10.1105/tpc.12.11.2129

Williams, P. M., and Barkan, A. (2003). A chloroplast-localized PPR protein required for plastid ribosome accumulation. Plant J. 3, 675-686. doi: 10.1046/j. 1365-313x.2003.01915.x

Yang, L., Zhang, J., He, J., Qin, Y., Hua, D., Duan, Y., et al. (2014). ABAMediated ROS in mitochondria regulate root meristem activity by controlling PLETHORA expression in Arabidopsis. PLoS Genet. 10:e1004791. doi: 10.1371/ journal.pgen.1004791

Zsigmond, L., Rigó, G., Szarka, A., Szekely, G., Otvos, K., Darula, Z., et al. (2008). Arabidopsis PPR40 connects abiotic stress responses to mitochondrial electron transport. Plant Physiol. 146, 1721-1737. doi: 10.1104/pp.107.111260 
Zybailov, B., Rutschow, H., Friso, G., Rudella, A., Emanuelsson, O., Sun, Q., et al. (2008). Sorting signals, N-terminal modifications and abundance of the chloroplast proteome. PLoS ONE 3:e1994. doi: 10.1371/journal.pone.0001994

Conflict of Interest Statement: The authors declare that the research was conducted in the absence of any commercial or financial relationships that could be construed as a potential conflict of interest.
Copyright (c) 2017 Nawaz and Kang. This is an open-access article distributed under the terms of the Creative Commons Attribution License (CC BY). The use, distribution or reproduction in other forums is permitted, provided the original author(s) or licensor are credited and that the original publication in this journal is cited, in accordance with accepted academic practice. No use, distribution or reproduction is permitted which does not comply with these terms. 